\title{
CRESCIMENTO E QUALIDADE DE MUDAS DE Anadenanthera macrocarpa (BENTH.) BRENAN EM RESPOSTA À SATURAÇÃO POR BASES DO SUBSTRATO ${ }^{1}$
}

\author{
Daíse Cardoso de Souza Bernardino², Haroldo Nogueira de Paiva ${ }^{3}$, Júlio César de Lima Neves ${ }^{4}$, \\ José Mauro Gomes ${ }^{3}$ e Vanderléia Braga Marques ${ }^{2}$
}

\begin{abstract}
RESUMO - O presente trabalho foi desenvolvido com o objetivo de verificar a influência da saturação por bases do substrato sobre o crescimento e a qualidade de mudas de Anadenanthera macrocarpa (angico-vermelho). O delineamento experimental utilizado foi inteiramente casualizado, com quatro repetições por tratamento. Foram empregados três solos como substrato, e para cada um deles a saturação por bases original foi elevada aos seguintes valores: Latossolo Distrófico, 30,0; 50,0; e 70,0\%; Latossolo Álico, 25,0; 45,0; e 65,0\%; e Argissolo, 50,0; 60,0; e 70,0\%. Foram avaliados os parâmetros morfológicos das mudas, suas relações e o índice de qualidade de Dickson. A saturação por bases não teve influência em nenhum dos parâmetros avaliados quando o substrato utilizado foi o argissolo. Exceto no diâmetro do coleto, a elevação da saturação por bases exerceu influência significativa, com padrão linear sobre os parâmetros morfológicos, suas relações e no índice de qualidade de Dickson para mudas produzidas no Latossolo Distrófico. No Latossolo Álico foi observado influência significativa com um comportamento quadrático sobre as características avaliadas, sendo os melhores crescimentos e qualidade encontrados quando a saturação por bases estava próxima de $50,0 \%$.
\end{abstract}

Palavras-chave: Saturação por bases, qualidade de mudas e angico-vermelho.

\section{GROWTH AND SEEDLING QUALITY OF Anadenanthera Macrocarpa (BENTH.) BRENAN IN RESPONSE TO BASIS SATURATION OF SUBSTRATUM}

\begin{abstract}
The present work was developed with the objective of verifying the influence of the basis saturation of substratum on the growth and seedling quality of Anadenanthera macrocarpa (angico-vermelho). A complete randomized design with four replications per treatment was utilized. Three soils were used as substratum, and for each the original saturation was risen to the following values: Distrofic Latosol, 30.0, 50.0 and 70.0\%; Alic Latosol, 25.0, 45.0 and 65.0\%; Claysoil, 50.0, 60.0 and 70.0\%. Seedlings morphological parameters were evaluated, their relationships and the Dickson's quality index. The base saturation had no influence on any of the studied parameters when the argisoil substratum was used. Except for the diameter, the rise in base saturation affected significantly, in a linear way, the morphological parameters and its relationships, as well the Dickson's quality index for seedlings produced in the distrofic latosol. For the alic latosol the best results for growth and quality were found with $50.0 \%$ base saturation.
\end{abstract}

Keywords: Base saturation, seedling quality and angico-vermelho.

\footnotetext{
${ }^{1}$ Recebido em 30.08.2004 e aceito para publicação em 10.08.2005.

${ }^{2}$ Programa de Pós-Graduação em Ciência Florestal da Universidade Federal de Viçosa - UFV, 36570-000 Viçosa - MG.

${ }^{3}$ Departamento de Engenharia Florestal da UFV. E-mail: <hnpaiva@ufv.br>.

${ }^{4}$ Departamento de Solos da UFV.
} 


\section{INTRODUÇÃO}

O maior entrave para o uso de espécies florestais nativas em plantios comerciais ou na recuperação de áreas degradadas tem sido a falta de estudos envolvendo a absorção de nutrientes e os requerimentos nutricionais dessas espécies, bem como sua sensibilidade a condições distintas de estresses químico ou físico (FURTINI NETO et al., 1995).

Para produzir mudas selecionadas com características ideais de desenvolvimento e que visem garantir o sucesso na produção do futuro povoamento florestal, inúmeros pesquisadores têm voltado seus estudos para o controle e a obtenção de mudas de boa qualidade capazes de resistir às adversidades ambientais após o plantio e sejam de baixo custo. As linhas de pesquisas voltadas para esse fim vão desde técnicas de produção de mudas de alto padrão de qualidade, análise de diferentes tipos de recipientes e substratos, bem como do tipo e da dose de fertilização e dos métodos de propagação de espécies florestais.

De acordo com Fonseca (2000), a obtenção de mudas de qualidade antes do plantio definitivo pode ser alcançada de maneira prática, rápida e fácil somente pela observação dos parâmetros morfológicos, definindo uma muda de qualidade como aquela que sobreviva e se desenvolva após o plantio no campo.

Cabe ressaltar que as práticas de manejo no viveiro podem alterar a qualidade das mudas, e variações no regime hídrico e na nutrição mineral podem ser usadas para aumentar ou diminuir o crescimento das plantas, de acordo com a necessidade (JOHNSON, 1986).

Tem sido amplamente observado que expressivos aumentos no crescimento e qualidade de mudas de essências florestais podem ser alcançados pela adoção de técnicas de fertilização do solo. Novais et al. (1979), trabalhando com Eucalyptus grandis em dois latossolos, concluíram que o uso da calagem em solos pobres proporcionou resposta significativa e positiva na planta.

Anadenanthera macrocarpa é a espécie de angico com maior abrangência geográfica, ocorrendo desde o sul da Bolívia até o norte da Argentina; no Brasil, só não aparece nos estados da Região Sul, sendo uma espécie comprovadamente calcícola, de crescimento rápido e tolerante a solos arenosos e rasos e muito usada para recomposição de matas ciliares (CARVALHO, 1994).

Objetivou-se, com este trabalho, verificar a influência da saturação por bases sobre o crescimento e qualidade de mudas de Anadenanthera macrocarpa em três diferentes substratos.

\section{MATERIAL E MÉTODOS}

O experimento foi instalado no Viveiro de Pesquisas Florestais do Departamento de Engenharia Florestal da Universidade Federal de Viçosa (UFV), Viçosa, MG.

A espécie utilizada foi Anadenanthera macrocarpa, cujas sementes foram obtidas no Laboratório de Análises de Sementes Florestais do Setor de Silvicultura do Departamento de Engenharia Florestal da UFV e inoculadas com mistura de estirpes de Bradyrhizobium, obtidas no Centro Nacional de Pesquisas em Agrobiologia (EMBRAPA), Seropédica, RJ.

O substrato utilizado foi terra de subsolo, originada de dois latossolos (um distrófico e outro álico) e um argissolo, cujas características químicas podem ser observadas no Quadro 1, coletados na camada abaixo de 30 a $70 \mathrm{~cm}$, na região de Viçosa. Esses solos foram secados ao ar, peneirados com malha de $4 \mathrm{~mm}$ e colocados em sacos com capacidade para $2 \mathrm{~kg}$ de solo cada.

Quadro 1 - Características químicas dos substratos Table 1 -Chemical characteristics of the substrata

\begin{tabular}{|c|c|c|c|c|c|c|c|c|c|c|}
\hline \multirow[t]{2}{*}{ Substrato } & $\mathrm{pH}$ & $\mathrm{P}$ & $\mathrm{K}$ & $\mathrm{Ca}$ & $\mathrm{Mg}$ & $\mathrm{Al}$ & $\mathrm{H}+\mathrm{Al}$ & $(\mathrm{T})$ & $\mathrm{m}$ & $\mathrm{V}$ \\
\hline & $\left(\mathrm{H}_{2} \mathrm{O}\right)$ & \multicolumn{2}{|c|}{$\mathrm{mg} / \mathrm{dm}^{3}$} & \multicolumn{5}{|c|}{$\mathrm{cmol}_{\mathrm{c}} / \mathrm{dm}^{3}$} & \multicolumn{2}{|c|}{$\%$} \\
\hline Argissolo & 5,64 & 1,50 & 16,00 & 1,74 & 0,17 & 0,00 & 3,00 & 4,95 & 0,00 & 39,40 \\
\hline Latossolo distrófico & 5,40 & 2,50 & 26,00 & 0,17 & 0,09 & 0,00 & 2,00 & 2,33 & 0,00 & 14,20 \\
\hline Latossolo álico & 4,73 & 0,90 & 10,00 & 0,14 & 0,03 & 1,20 & 5,30 & 5,50 & 85,70 & 3,60 \\
\hline
\end{tabular}

pH em água - relação 1:2,5; P, K - Extrator Mehlich 1; Ca, Mg, Al - Extrator KCl - 1 mol/L; H + Al - Extrator Acetato de Cálcio $0,5 \mathrm{~mol} / \mathrm{L}$ - pH 7,0; $(\mathrm{T})=$ Capacidade de troca catiônica a pH 7,0; V = Índice de saturação por bases; e $\mathrm{m}=$ Índice de saturação por alumínio.

R. Árvore, Viçosa-MG, v.29, n.6, p.863-870, 2005 
A saturação por bases original de cada solo foi elevada para três diferentes valores, pelo método da elevação da saturação por bases (Quadro 2), através da seguinte fórmula:

$$
\mathrm{NC}(\mathrm{t} / \mathrm{ha})=\left(\mathrm{V}_{2}-\mathrm{V}_{1}\right) \mathrm{T} / 100
$$

em que:

$\mathrm{NC}=$ necessidade de calagem, em toneladas por hectare;

$\mathrm{V}_{2}=$ porcentagem de saturação por bases desejada;

$\mathrm{V}_{1}=$ porcentagem de saturação por bases do solo, conforme análise; e

$$
\mathrm{T}=\text { capacidade de troca catiônica, a pH 7,0. }
$$

O corretivo utilizado foi uma mistura de carbonato de cálcio, $\mathrm{CaCO}_{3}$ e carbonato de magnésio, $\mathrm{MgCO}_{3}$, na relação estequiométrica $4: 1$; após a incorporação do corretivo, o solo ficou incubado por 30 dias, com a umidade sendo mantida em torno de $60,0 \%$ da capacidade de campo, inclusive para o tratamento sem calcário.

Após 30 dias de incubação, os solos receberam adubação básica, em solução, nas seguintes doses: $300 \mathrm{mg} / \mathrm{dm}^{3}$ de fósforo, $100 \mathrm{mg} / \mathrm{dm}^{3}$ de potássio, 100 $\mathrm{mg} / \mathrm{dm}^{3}$ de nitrogênio e $40 \mathrm{mg} / \mathrm{dm}^{3}$ de enxofre, usandose como fontes $\mathrm{NaH}_{2} \mathrm{PO}_{4} \cdot \mathrm{H}_{2} \mathrm{O}, \mathrm{KCl}, \mathrm{NH}_{4} \mathrm{NO}_{3}$ e $\mathrm{K}_{2} \mathrm{SO}_{4}$, conforme sugerido por Passos (1994); e solução de micronutrientes, nas seguintes doses: $0,81 \mathrm{mg} / \mathrm{dm}^{3} \mathrm{de}$ boro $\left(\mathrm{H}_{3} \mathrm{BO}_{3}\right), 1,33 \mathrm{mg} / \mathrm{dm}^{3}$ de cobre $\left(\mathrm{CuSO}_{4} .5 \mathrm{H}_{2} \mathrm{O}\right), 0,15$ $\mathrm{mg} / \mathrm{dm}^{3}$ de molibdênio [ $\left.\left(\mathrm{NH}_{4}\right)_{6} \mathrm{Mo}_{7} \mathrm{O}_{24} \cdot 4 \mathrm{H}_{2} \mathrm{O}\right], 3,66 \mathrm{mg} /$ $\mathrm{dm}^{3}$ de manganês $\left(\mathrm{MnCl}_{2} \cdot \mathrm{H}_{2} \mathrm{O}\right)$ e $4,0 \mathrm{mg} / \mathrm{dm}^{3}$ de zinco $\left(\mathrm{ZnSO}_{4} \cdot 7 \mathrm{H}_{2} \mathrm{O}\right)$, de acordo com Alvarez V. (1974); e foram dispostos em vasos de polietileno rígido com capacidade para $2 \mathrm{~kg}$ de solo.

Quadro 2 - Valores de saturação por bases para cada um dos substratos*

Table 2 - Base saturation values for each substratum

\begin{tabular}{lcccc}
\hline Substrato & Tratam. & Tratam. & Tratam. & Tratam. \\
& 1 & 2 & 3 & 4 \\
\hline Argissolo & $39,4 \%$ & $50,0 \%$ & $60,0 \%$ & $70,0 \%$ \\
Latossolo distrófico & $14,2 \%$ & $30,0 \%$ & $50,0 \%$ & $70,0 \%$ \\
Latossolo álico & $3,6 \%$ & $25,0 \%$ & $45,0 \%$ & $65,0 \%$ \\
\hline
\end{tabular}

* Tratamento $1=$ valores medidos. Tratamento $2=$ valores esperados após a adição de $\mathrm{CaCO}_{3}$ e $\mathrm{MgCO}_{3}$ para a elevação da saturação por bases.
Além da adubação básica, foram realizadas duas adubações nitrogenadas, aos 30 e 60 dias após a semeadura, na dose de $20 \mathrm{mg} / \mathrm{dm}^{3}$ de $\mathrm{N}$, por aplicação, utilizando-se como fonte $\mathrm{o} \mathrm{NH}_{4} \mathrm{NO}_{3}$.

A semeadura foi efetuada diretamente nos vasos, colocando-se 10 sementes por vaso; 15 dias após a emergência foi feito o raleio, deixando-se apenas a plântula mais bem desenvolvida e mais central.

Os parâmetros morfológicos das mudas e suas relações utilizadas nas avaliações dos resultados foram a altura da parte aérea (H), o diâmetro do coleto (DC), o peso de matéria seca total (PMST), o peso de matéria seca da parte aérea (PMSPA), o peso de matéria seca das raízes (PMSR), a relação entre altura e diâmetro do coleto (H/DC), a relação entre altura e peso de matéria seca da parte aérea (H/PMSPA), a relação entre peso de matéria seca da parte aérea e peso de matéria seca das raízes (PMSPA/PMSR) e o índice de qualidade de Dickson (IQD) (DICKSON et al., 1960).

A partir da semeadura foram contados, para o final do experimento, 100 dias, quando se mediram as características altura $(\mathrm{H})$, com régua com precisão de $0,01 \mathrm{~cm}$; e diâmetro do coleto (DC), com paquímetro digital com precisão de $0,01 \mathrm{~mm}$.

As plantas, então, foram separadas em raiz e parte aérea, sendo o sistema radicular lavado com água destilada. O material foi colocado em sacos de papelpardo e levado para estufa com circulação de ar forçada a $60{ }^{\circ} \mathrm{C}$, por 72 horas, sendo, então, pesado em balança analítica com precisão de $0,01 \mathrm{~g}$, para as determinações dos parâmetros peso de matéria seca da parte aérea (PMSPA) e peso de matéria seca das raízes (PMSR), e a soma dos dois forneceu o peso de matéria seca total (PMST). O índice de qualidade de Dickson (IQD) é igual à PMST/(H/DC + PMSPA/PMSR).

Os dados foram interpretados estatisticamente, por meio de análises de variância e regressão. Os modelos foram escolhidos com base no coeficiente de determinação e na significância dos coeficientes de regressão, adotando-se o nível de $5 \%$ de probabilidade e utilizando o teste " $\mathrm{t}$ ", de Student.

As análises estatísticas foram realizadas utilizandose o programa SAEG (Sistema de Análises Estatística e Genética), desenvolvido pela UFV (1997).

R. Árvore, Viçosa-MG, v.29, n.6, p.863-870, 2005 


\section{RESULTADOS E DISCUSSÃO}

No Quadro 3 e nas Figuras 1, 2 e 3, observa-se que a elevação da saturação por bases não teve influência significativa em nenhum dos parâmetros avaliados, quando o substrato utilizado foi o argissolo. Essa falta de resposta pode estar relacionada aos teores iniciais de $\mathrm{Ca}^{2+}\left(1,74 \mathrm{cmol}_{\mathrm{c}} / \mathrm{dm}^{3}\right)$ e $\mathrm{Mg}^{2+}\left(0,17 \mathrm{cmol}_{\mathrm{c}} / \mathrm{dm}^{3}\right)$ no solo, que já seriam suficientes para suprir as necessidades dessa espécie, durante a fase de muda. Resultados semelhantes também foram observados por Dias et al. (1990, 1991), Baliero et al. (1995) e Gomes (2002), trabalhando com diferentes espécies florestais.

As mudas produzidas utilizando-se o latossolo distrófico como substrato tiveram relação direta entre os parâmetros avaliados e o aumento da saturação por bases no solo, exceto para o diâmetro do coleto, em que a saturação por bases não exerceu influência significativa (Quadro 3 e Figura 1). Esse resultado é semelhante ao encontrado por Baliero et al. (2001) e Reis et al. (1997), que o justificaram devido à baixa exigência de cálcio das espécies na fase juvenil. No latossolo álico houve resposta positiva para o diâmetro do coleto com uma distribuição quadrática (Figura 1), com ponto de máximo na saturação por bases de 46,0\%.

A altura da parte aérea foi influenciada pela elevação da saturação por bases nos dois latossolos, assumindose comportamento linear no latossolo distrófico e quadrático para o latossolo álico (Figura 1). No Quadro
3, pode-se observar que a elevação da saturação por bases no latossolo distrófico e no latossolo álico possibilitaram incremento em altura.

Esse comportamento é diferente do encontrado por Baliero et al. (2001), que não verificaram influência da saturação por bases no incremento em altura nas espécies Acacia holosericea e Acacia auriculiformis, justificando isso devido ao fato de espécies de crescimento rápido, em geral, terem menor requerimento nutricional e serem tolerantes a condições de acidez.

O peso de matéria seca da parte aérea, do sistema radicular e total foi influenciado positivamente pela elevação da saturação por bases nos dois latossolos. A produção de matéria seca tem sido considerada um dos melhores parâmetros para caracterizar a qualidade de mudas, apresentando, porém, o inconveniente de não ser viável a sua determinação em muitos viveiros, principalmente por envolver a destruição completa da muda e a utilização de estufas (AZEVEDO, 2003).

A influência da saturação por bases no peso de matéria seca total teve comportamento linear no latossolo distrófico e quadrática no latossolo álico (Quadro 3), com ponto de máximo na saturação de 47,0\%. Avaliando o padrão de qualidade de mudas de Araucaria angustifolia, Malinovski (1977) reportou que o peso de matéria seca total é importante para a qualidade das mudas e que nessa espécie não deve ultrapassar $2,0 \mathrm{~g}$.

Quadro 3 - Médias de altura (H), diâmetro do coleto (DC), peso de matéria seca das raízes (PMSR), peso de matéria seca da parte aérea (PMSPA) e peso de matéria seca total (PMST) das mudas de angico-vermelho em resposta à saturação por bases do substrato, 100 dias após a semeadura

Table 3 - Means of height $(H)$, stem diameter $(D C)$, root dry matter (PMSR), dry matter of the aerial part (PMSPA) and total dry matter weight (PMST) of the angico-vermelho seedlings in response to the base saturation of the substratum, at 100 days after planting

\begin{tabular}{|c|c|c|c|c|c|c|}
\hline & $\begin{array}{c}\text { Saturação } \\
\%\end{array}$ & $\begin{array}{c}\text { Altura } \\
\mathrm{cm}\end{array}$ & $\begin{array}{c}\text { Diâmetro } \\
\mathrm{mm}\end{array}$ & PMSR & $\begin{array}{c}\text { PMSPA } \\
-\mathrm{g} \\
\end{array}$ & PMST \\
\hline & 14,20 & 19,80 & 2,85 & 0,87 & 0,86 & 1,73 \\
\hline Latossolo & 30,00 & 30,18 & 3,06 & 1,00 & 1,20 & 2,20 \\
\hline \multirow[t]{3}{*}{ distrófico } & 50,00 & 38,50 & 4,16 & 3,71 & 3,12 & 6,83 \\
\hline & 70,00 & 47,55 & 4,35 & 4,25 & 4,21 & 8,45 \\
\hline & 3,60 & 37,27 & 3,86 & 1,96 & 2,73 & 4,69 \\
\hline \multirow{4}{*}{$\begin{array}{l}\text { Latossolo } \\
\text { álico }\end{array}$} & 25,00 & 58,88 & 6,31 & 7,77 & 6,65 & 14,42 \\
\hline & 45,00 & 71,23 & 6,90 & 9,33 & 8,08 & 17,40 \\
\hline & 65,00 & 57,53 & 6,40 & 8,87 & 6,69 & 15,56 \\
\hline & 39,40 & 67,50 & 5,98 & 4,98 & 9,24 & 14,22 \\
\hline \multirow[t]{3}{*}{ Argissolo } & 50,00 & 48,08 & 5,49 & 4,38 & 6,26 & 10,64 \\
\hline & 60,00 & 49,90 & 5,10 & 3,23 & 4,72 & 7,95 \\
\hline & 70,00 & 64,20 & 5,84 & 4,68 & 6,76 & 11,43 \\
\hline
\end{tabular}

R. Árvore, Viçosa-MG, v.29, n.6, p.863-870, 2005 

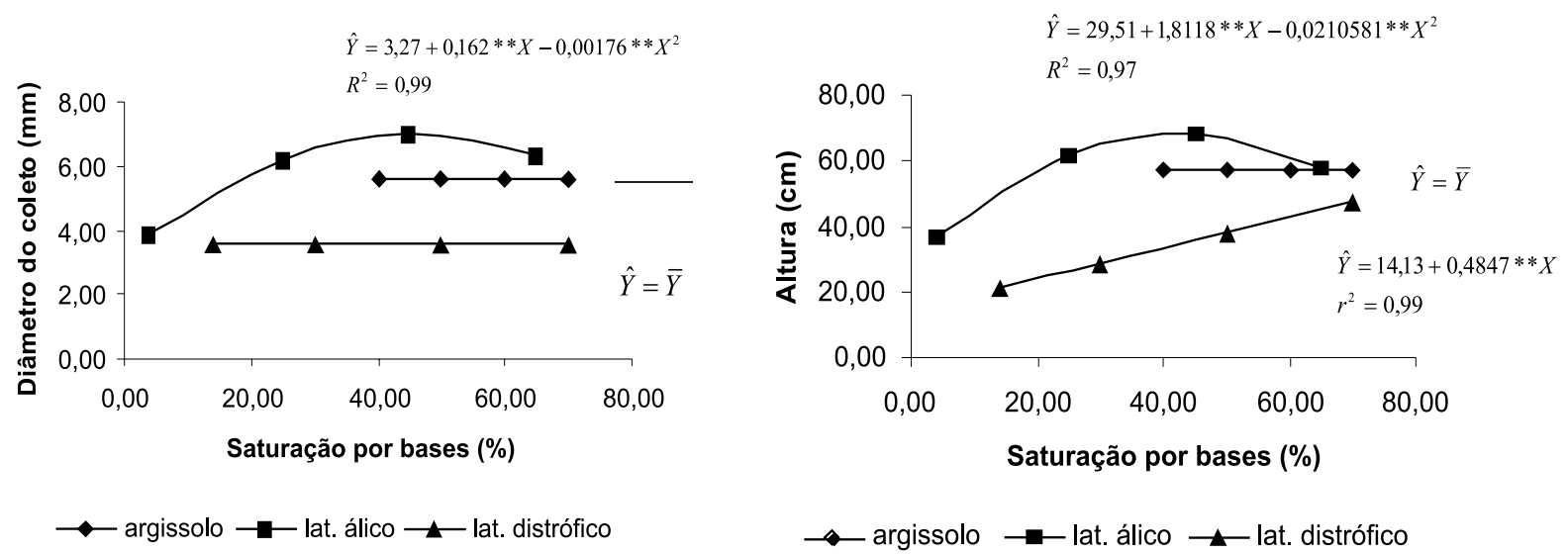

Figura 1 - Variações da H e DC das mudas de A. macrocarpa em função da saturação por bases do substrato.

Figure 1 -Variations of $H$ and DC of A. macrocarpa seedlings as a function of the base saturation of the substratum.

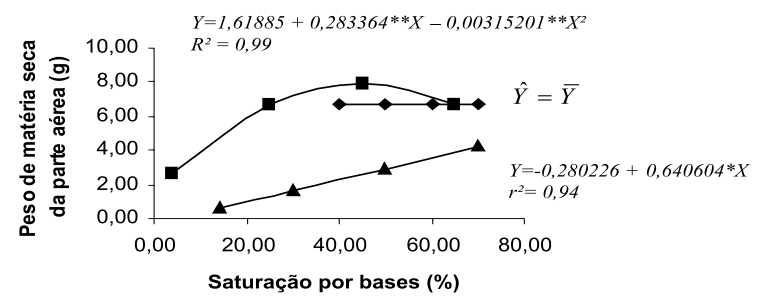

$\multimap$ argissolo $\longrightarrow$ lat. álico $\multimap$ lat. distrófico
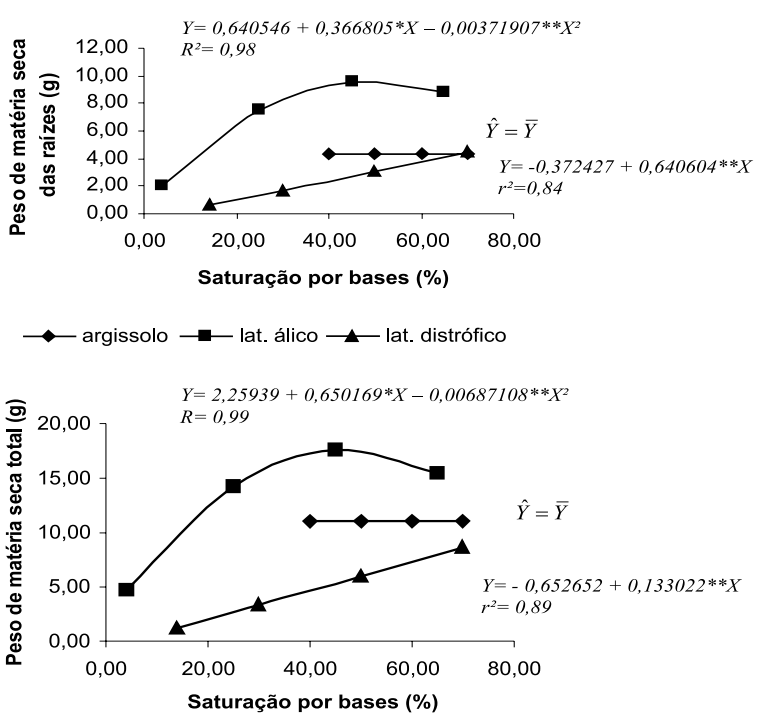

Figura 2 - Variações da PMSPA, PMSSR e PMST das mudas de A. macrocarpa em função da saturação por bases do substrato.

Figure 2 - Variations of PMSPA, PMSSR and PMST of A. macrocarpa seedlings as a function of the base saturation of the substratum.
A exemplo das características anteriores, com relação a peso de matéria seca da parte aérea foram observados comportamentos linear do latossolo distrófico e quadrático do latossolo álico, alcançando ponto de máximo quando a saturação por bases desse solo era de 45,0\%. Essas respostas positivas dos parâmetros morfológicos para a elevação da saturação por bases apontam a necessidade de se fazer a correção da acidez do solo para obter mudas de qualidade para o angicovermelho.

De acordo com Hermann (1964), o peso de matéria seca das raízes tem sido reconhecido como um dos melhores e mais importantes parâmetros para a sobrevivência e estabelecimento das mudas no campo. Em mudas de Pseudotsuga menziesii, a sobrevivência foi consideravelmente maior quanto mais abundante foi o sistema radicular, independentemente da altura da parte aérea. Analisando esse parâmetro, observouse comportamentos linear do latossolo distrófico e quadrático do latossolo álico, onde o valor máximo foi alcançado na saturação por bases de 49,0\% (Quadro 3 e Figura 2).

A resposta das relações entre os parâmetros morfológicos ocorreu de maneira diferenciada nos três substratos (Quadro 4), não tendo ocorrido influência significativa da saturação por bases no argissolo e no latossolo distrófico. No latossolo álico, a relação entre altura e diâmetro do coleto não foi afetada significativamente (Figura 3). A altura da parte aérea da muda combinada com o respectivo diâmetro do coleto constitui-se num dos mais importantes parâmetros

R. Árvore, Viçosa-MG, v.29, n.6, p.863-870, 2005 
morfológicos para estimar o crescimento das mudas após o plantio definitivo no campo (CARNEIRO, 1995). Pode-se inferir que esta resposta não significativa se deve ao fato do crescimento da altura da parte aérea e do diâmetro do coleto ter ocorrido de forma equilibrada para todas as saturações.
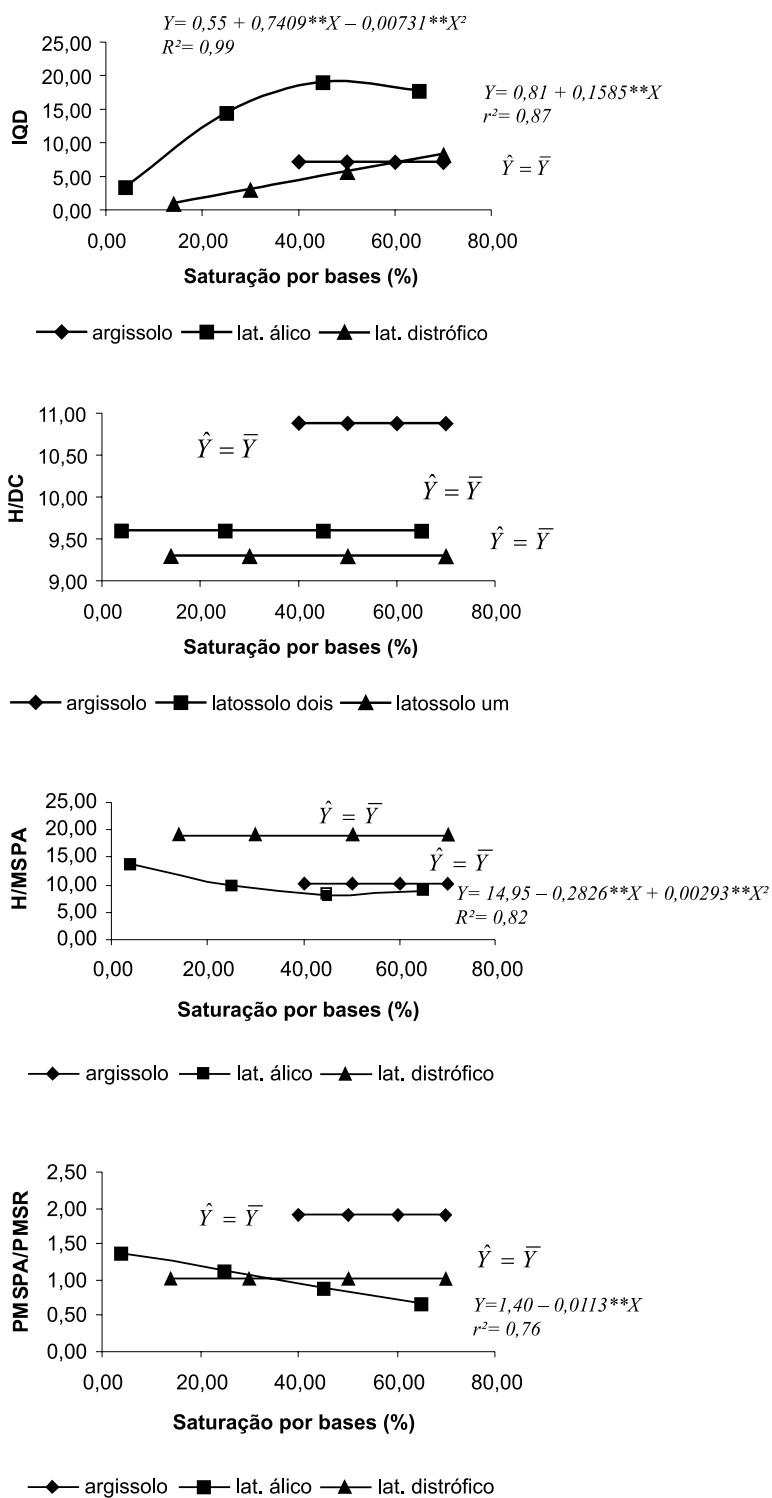

Figura 3-Variação das relações IQD, H/DC, H/PMSPAe PMSPA/ PMSR de A. macrocarpa em função da saturação por bases do substrato.

Figure 3 - Variation of ratios IQD, H/DC, H/PMSPA and PMSPA/PMSR of A. macrocarpa seedlings as a function of the base saturation of the substratum.

R. Árvore, Viçosa-MG, v.29, n.6, p.863-870, 2005
De acordo com Gomes (2001), quanto menor o quociente obtido pela divisão da altura da parte aérea pelo peso de matéria seca da parte aérea mais rustificada será a muda e maior deverá ser sua sobrevivência no campo. Para o Latossolo 2 a resposta desse quociente à elevação da saturação por bases foi significativa, encontrando ponto de mínimo na saturação por bases de 48,0\% (Figura 3). Esse quociente não tem sido muito utilizado para avaliar a qualidade de mudas, mas pode ser usado para predizer seu potencial de sobrevivência.

Para a relação entre o peso de matéria seca da parte aérea e o peso de matéria seca do sistema radicular, foi observado comportamento quadrático, e, de acordo com Brissette (1984), citado por Azevedo (2003), a melhor relação entre esses parâmetros deve ter valor 2,0. De acordo com os resultados, o valor que mais se aproximou do ótimo foi encontrado na saturação por bases originais do solo, sendo reduzida a sua elevação, atingindo seu mínimo na saturação de 45,0\%, e observado, assim, um efeito negativo na distribuição de biomassa em função da saturação por bases do solo (Figura 3 ).

Quadro 4 - Médias das relações altura/diâmetro do coleto, altura/peso de matéria seca da parte aérea e peso de matéria seca da parte aérea/peso de matéria seca das raízes e do índice de qualidade de Dickson das mudas de angico-vermelho em resposta à saturação por bases do substrato, 100 dias após a semeadura

Table 4-Means of the ratio height/stem diameter (H/DC), height /dry matter of the aerial part (H/PMSPA) and dry matter weight of the aerial part/dry matter weight of roots (PMSPA/PMSR), and of the Dickson's quality index (IQD) of angico-vermelho seedlings in response to the base saturation of the substratum, at 100 days after planting

\begin{tabular}{lccccc}
\hline & $\begin{array}{c}\text { Saturação } \\
(\%)\end{array}$ & $\begin{array}{c}\mathrm{H} / \\
\mathrm{DC}\end{array}$ & $\begin{array}{c}\mathrm{H} / \\
\text { PMSPA }\end{array}$ & $\begin{array}{c}\text { PMSPA/ } \\
\text { PMSR }\end{array}$ & IQD \\
\hline \multirow{3}{*}{ Argissolo } & 39,4 & 11,30 & 7,53 & 2,84 & 8,07 \\
& 50,0 & 8,71 & 12,59 & 1,46 & 6,90 \\
& 60,0 & 9,85 & 10,69 & 1,52 & 5,12 \\
& 70,0 & 10,93 & 9,88 & 1,86 & 8,57 \\
\hline \multirow{4}{*}{ Latossolo } & 14,20 & 6,69 & 25,15 & 0,97 & 1,55 \\
distrófico & 30,00 & 9,90 & 26,45 & 1,22 & 1,69 \\
& 50,00 & 9,79 & 13,36 & 0,91 & 7,20 \\
& 70,00 & 10,82 & 11,69 & 1,04 & 7,89 \\
\hline \multirow{2}{*}{ Latossolo } & 3,60 & 7,18 & 10,64 & 1,16 & 2,37 \\
álico & 25,00 & 9,34 & 9,10 & 0,89 & 15,25 \\
& 45,00 & 10,36 & 8,80 & 0,89 & 18,32 \\
& 65,00 & 9,08 & 8,74 & 0,75 & 18,08 \\
\hline
\end{tabular}


O índice de qualidade de Dickson foi influenciado positivamente pela elevação da saturação por bases (Tabela 4 e Figura 3), estando as melhores mudas na saturação de 70,0\% para o latossolo distrófico e na saturação de 50,0\% para o latossolo álico, uma vez que, quanto maior o índice de qualidade de Dickson, melhor a qualidade das mudas (GOMES, 2001).

\section{CONCLUSÕES}

Não há efeito significativo da elevação da saturação por bases sobre os parâmetros morfológicos e suas relações na produção de mudas de angico-vermelho quando se utiliza como substrato o argissolo.

A elevação da saturação por bases do substrato proporciona melhora na qualidade de mudas de angicovermelho quando se utilizam os latossolos distrófico e álico.

\section{REFERÊNCIAS BIBLIOGRÁFICAS}

ALVAREZ V., V.H. Equilíbrio de formas disponíveis de fósforo e enxofres em dois latossolos de Minas Gerais. 1974. 125f. Dissertação (Mestrado em Solos e Nutrição de Plantas) - Universidade Federal de Viçosa, Viçosa, 1974.

AZEVEDO, M.I.R. Qualidade de mudas de cedro-rosa (Cedrela fissilis Vell.) e de ipê-amarelo (Tabebuia serratifolia (Vahl) Nich.) produzidas em diferentes substratos e tubetes. 2003. 90f. Dissertação (Mestrado em Ciência Florestal) - Universidade Federal de Viçosa, Viçosa, 2003.

BALIERO, F.C., OLIVEIRA, I.G., DIAS, L.E. Formação de mudas de Acacia holocericea: resposta à calagem, fósforo, potássio e enxofre. In: CONGRESSO BRASILEIRO DE CIÊNCIA DO SOLO, 25., 1995, Viçosa, MG. Resumos... Viçosa, MG: SBCS, 1995. p. 830-832.

BALIERO, F.C.; OLIVEIRA, I.G.; DIAS, L.E. Formação de mudas de Acacia holosericea e Acacia auriculiformis: resposta à calagem, fósforo, potássio e enxofre. Revista Árvore, v.25, n.2, p.183-191, 2001.

CARneiro, J. G. A. Produção e controle de qualidade de mudas florestais. Curitiba: UFPR/FUPEF, 1995. 451 p.
CARVALHO, P.E.R. Espécies florestais brasileiras: recomendações

silviculturais, potencialidades e uso da madeira. Colombo: EMBRAPA - CNPF; Brasília: EMBRAPA - SPI, 1994. 640p.

DIAS, L.E.; ALVARES V., V.H.; BRIENZA JR, S. Formação de mudas de Acacia mangium: I. resposta a calcário e fósforo. In: CONGRESSO FLORESTAL BRASILEIRO, 6., 1990, Campos do Jordão. Anais... Campos do Jordão: SBS, SBEF, 1990. p.449-453, 801p.

DIAS, L.E. et al. Formação de mudas de táxi-branco (Sclerolobium paniculatum Voguel). I. Resposta a calcário e fósforo. Pesquisa Agropecuária Brasileira, v.26, n.1, p.66-76, 1991.

DICKSON, A.; LEAF, A.L.; HOSNER, J.F. Quality appraisal of white spruce and white pine seedling stock in nurseries. Forest Chronicle, v. 36, p.10-13, 1960

FONSECA, E.P. Padrão de qualidade de mudas de Trema micrantha (L.) Blume., Cedrela fissilis Vell. E Aspidosperma polyneuron Müll. Arg. Produzidas sob diferentes períodos de sombreamento. 2000. 113f. Tese (Doutorado em Agronomia) Universidade Estadual Paulista, Jaboticabal, 2000.

FURTINI NETO, A.E. et al. Efeito da calagem no crescimento de espécies nativas na fase de mudas. In: CONGRESSO BRASILEIRO DE CIÊNCIA DO SOLO, 25., 1995, Viçosa, MG. Resumos expandidos... Viçosa, MG: SBCS/ UFV, 1995. v. 2. p.827-829.

GOMES, J. M. Parâmetros morfológicos na avaliação da qualidade de mudas de Eucalyptus grandis, produzidas em diferentes tamanhos de tubete e de dosagens de N-P-K. 2001.166f. Tese (Doutorado em Ciência Florestal) - Universidade Federal de Viçosa, Viçosa, 2001.

GOMES, K.C.O. Influência da saturação por bases e do fósforo no crescimento enutrição mineral de mudas de angico-branco e garapa. 2002. 68f. Dissertação (Mestrado em Ciência Florestal) Universidade Federal de Viçosa, Viçosa, 2002.

HERMANN, R. K. Importance of top-root ratios for survival of Douglas-fir seedling. Tree Planter's Notes, v. 64, p.711,1964.

R. Árvore, Viçosa-MG, v.29, n.6, p.863-870, 2005 
JOHNSON, C.J. How to use seedling quality measurement in container nurseries. In: INTERMOUNTAIN NURSERYMAN'S ASSOCIATION MEETING, 1985, Fort Collins. Proceedings... Fort Collins: USDA Forest Service, 1986. p.84-86.

MALINOVSKI, J. R. Método de poda radicular em Araucaria angustifolia Bert. 0. Ktze. e seus efeitos sobre a qualidade de mudas em raiz nua. Revista Floresta, v.8, n.1, p.85-88, 1977.

NOVAIS, R.F. et al. Calagem e adubação mineral na produção de mudas de eucalipto (Eucalyptus grandis W. Hill ex. Maiden). I. Efeitos da calagem e dos nutrientes N, P e K. Revista Árvore, v.3., n.2, p.121-34, 1979.
PASSOS, M.A.A. Efeito da calagem e de fósforo no crescimento inicial da algaroba (Prosopis juliflora (SW) DC). 1994. 57f. Tese (Doutorado em Fitotecnia) Universidade Federal de Viçosa, Viçosa, 1994.

REIS, M.G.F. et al. Exigências nutricionais de mudas de Dalbergia nigra (Vell.) Fr. Allem (jacarandá-da-Bahia) produzidas em dois níveis de sombreamento. Revista Árvore, v.21, n.4, p.463-471, 1997.

UNIVERSIDADE FEDERAL DE VIÇOSA - UFV. SAEG - Sistema de análises estatísticas e genéticas. Versão 7.1. Viçosa, MG: 1997. 150p. (Manual do usuário). 